\section{TRIIODOTHYRONINE IMPROVES LEFT VENTRICULAR FUNCTION WITHOUT OXYGEN WASTING EFFECTS AFTER GLOBAL HYPOTHERMIC ISCHEMIA}

From the Department of Cardiothoracic Surgery, New York Hospital-Cornell University Medical College, ${ }^{a}$ New York, N.Y., and the Department of Medicine/Division of Endocrinology, North Shore University Hospital-Cornell University Medical College, ${ }^{\mathrm{b}}$ Manhasset, N.Y.

Received for publication April 28, 1994.

Accepted for publication July 19, 1994.

Address for reprints: John D. Klemperer, MD, Department of Cardiothoracic Surgery, New York Hospital-Cornell University Medical College, Room A-827, 525 E. 68th St., New York, NY 10021.

Copyright $\odot 1995$ by Mosby-Year Book, Inc. $0022-5223 / 95 \$ 3.00+0 \quad \mathbf{1 2 / 1 / 5 9 3 4 6}$
Cardiopulmonary bypass results in a "euthyroid sick" state. Recently, interest has focused on the relationship between low serum triiodothyronine levels and postoperative cardiovascular hemodynamics. The present study was undertaken to more clearly define the acute effects of triiodothyronine on myocardial mechanics and energetics after hypothermic global ischemia using an ex-vivo canine heart preparation to model the clinical condition. Experiments were performed on isolated hearts subjected to hyperkalemic arrest with 90 minutes of hypothermic $\left(10^{\circ} \mathrm{C}\right)$ ischemia. Isolated hearts were cross-perfused by euthyroid support dogs in which triiodothyronine levels spontaneously decreased by $65 \%$ to $75 \%(p<0.01)$ after the initiation of cross-perfusion. In nine heart preparations, triiodothyronine (Triostat) was given as a bolus dose $(0.2 \mu \mathrm{g} / \mathrm{kg}$ ) after 1 hour of baseline data collection with a subsequent measurable rise in serum triiodothyronine levels $(p<0.01)$. In six postischemic hearts, reverse triiodothyronine was given as a $0.2 \mu \mathrm{g} / \mathrm{kg}$ bolus. Triiodothyronine was also administered to a group of eight nonischemic, continuously perfused isolated hearts. Intrinsic myocardial contractility was assessed by analysis of the preload recruitable stroke work area, energetic efficiency from the myocardial oxygen consumption-pressure-volume area relationship, and coronary vascular resistance from analysis of coronary flow and perfusion pressure. Acute administration of triiodothyronine to postischemic hearts improved the preload recruitable stroke work area from $9.5 \pm 1.42$ to $14.9 \pm 2.03 \times 10^{7} \mathrm{erg} / \mathrm{ml}$, a $56 \%$ increase from baseline $(p<0.001)$, but had no effect on the preload recruitable stroke work area of the nonischemic hearts. The inotropic response resulting from triiodothyronine treatment did not alter the myocardial oxygen consumption-pressure-volume area relationship. Triiodothyronine treatment was associated with significantly decreased coronary resistance and increased coronary flow through a range of diastolic loading conditions in the postischemic hearts. The biologically inactive thyroid hormone metabolite reverse triiodothyronine was without effect on any of the measured parameters. On the basis of these results, we conclude that the low triiodothyronine state of cardiopulmonary bypass can be reproduced in this isolated heart model and that acute triiodothyronine treatment results in a unique inotropic action manifest only in the postischemic reperfused myocardium and is accomplished without oxygen wasting effects. (J ThoraC CARDIOVASC SuRG 1995;109:457-65)

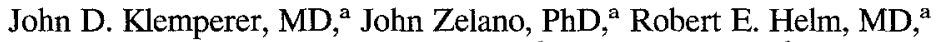

Karen Berman, BS, ${ }^{a}$ Kaie Ojamaa, $\mathrm{PhD},{ }^{\mathrm{b}}$ Irwin Klein, $\mathrm{MD},{ }^{\mathrm{b}} \mathrm{O}$. Wayne Isom, MD, and Karl Krieger, MD, ${ }^{\mathrm{a}}$ New York and Manhasset, N.Y.
T hyroid hormone has profound effects on the heart and cardiovascular system. ${ }^{1-4}$ Although the sequelae of chronic hyperthyroid and hypothyroid states are well documented, the effects of acute alterations in serum hormone levels have been less thoroughly characterized. Cardiopulmonary bypass (CPB) results in a "euthyroid sick" state, 5,6 and interest has focused on the relationship between low serum triiodothyronine $\left(T_{3}\right)$ levels and postoperative cardiovascular hemodynamics. Accumulating experimental data suggest that pharmacologic $T_{3}$ supplementation may improve hemodynamic parameters after ischemic injury in animal models of
$\mathrm{CPB}^{7-9}$ and in isolated heart studies. ${ }^{10,11}$ Limited clinical data also suggest a benefit to short-term $T_{3}$ supplementation in the peri-CPB period. ${ }^{12,13}$ The mechanism of action of $T_{3}$ in these settings remains uncharacterized, yet the rapid improvement in left ventricular function reveals the importance of extranuclear pathways. Because thyroid hormones are known to affect systemic vascular resistance, ${ }^{14,15}$ direct cardiac effects of $T_{3}$ are best measured with load-independent parameters of ventricular function. Published reports in which isolate heart models were used, however, have relied on severe warm ischemic injury and crystalloid perfusates and have 


\begin{tabular}{|l|c|c|cc|c|cc|c|}
\hline Stemotomy/Cardioplegia & Ischemia $10^{\circ} \mathrm{C}$ & Reperfusion & \multicolumn{2}{|c|}{ Baseline data } & T3 bolus & \multicolumn{3}{|c|}{ Post T3 data } \\
& & & set 1 & set 2 & & set 1 & set 2 & set 3 \\
\hline Duration (minutes): & 90 & 30 & 30 & 30 & 30 & 30 & 30 & 30
\end{tabular}

Fig. 1. Experimental protocol. The stages of the experiment are outlined with corresponding time intervals listed. Two data sets were collected during the baseline period and three during the posttreatment period.

not addressed the left ventricular pressure-volume area-oxygen consumption (PVA- $\mathrm{MVO}_{2}$ ) relationship. The present study was undertaken to delineate the acute effects of $T_{3}$ on myocardial mechanics and energetics after hypothermic global ischemia with a canine ex vivo isolated heart model used to mimic the clinical condition.

\section{Methods}

Operative procedures. All animals received humane care in compliance with the "Principles of Laboratory Animal Care" formulated by the National Society for Medical Research and the "Guide for the Care and Use of Laboratory Animals" prepared by the National Academy of Sciences and published by the National Institutes of Health (NIH Publication No. 86-23, revised 1985).

Individual experiments involved the use of two adult mongrel dogs as previously described. ${ }^{16}$ In each experiment, the heart of one animal was used as the ex vivo isolated heart preparation that was cross-perfused by the second $\operatorname{dog}$ as the support animal. The animals were allowed food and water ad libitum the night before the experiments to avoid acute alteration of thyroid hormone levels. Animals were sedated with acepromazine (0.1 $\mathrm{mg} / \mathrm{kg}$ intramuscularly) and anesthesia was induced with pentobarbital ( 25 to $30 \mathrm{mg} / \mathrm{kg}$ intravenously) and maintained with isoflurane $(0.4 \%$ to $1.5 \%)$. The animals were intubated and ventilated by a mechanical respirator. Cefazolin (Kefzol, $1 \mathrm{gm}$ intravenously) and indomethacin (50 $\mathrm{mg}$ by suppository) was given to each support animal at the onset of surgical intervention. The electrocardiogram and mean arterial blood pressure were continuously monitored.

Support animal and cross-circulation. An $8 \mathrm{~F}$ catheter was placed in the left femoral vein for fluid and drug administration. The animal was fully heparinized (400 $\mathrm{U} / \mathrm{kg}$ intravenous bolus, followed by a continuous infusion of $500 \mathrm{U} / \mathrm{hr}$ ). The circuit has been described in detail in an earlier report. ${ }^{16}$ In brief, the right femoral vessels were cannulated with $18 \mathrm{~F}$ cannulas (Bard Vascular Systems, Billerica, Mass.) and connected to the circuit with $3 / 8$-inch tubing. A double roller head pump (Masterflex/ColeParmer Instrument Co., Chicago, IIl.) was used to pump bidirectional flows of arterial and venous blood in synchronous flow rates, which were controlled by a custom servo device to maintain constant coronary perfusion pressure ( 70 to $80 \mathrm{~mm} \mathrm{Hg}$ ) to the ex vivo heart. The circuit required a prime volume of $500 \mathrm{ml}$ crystalloid solution before it was connected to the support animal. Hemodynamic stability was maintained by the infusion of fluids (crystalloid and dextran) when needed. Arterial $\mathrm{pH}$ was maintained within normal range by adjustment of the ventilator tidal volume and rate or the administration of sodium bicarbonate. Arterial inflow into the ex vivo heart's aorta and coronary sinus drainage were simultaneously measured by ultrasonic flow probes (Transonic, Ithica, N.Y.).

Ex vivo heart preparation/hypothermic ischemia model. Through a sternotomy incision, a pericardial cradle was created. The great vessels were isolated and surrounded by sutures or tapes. After heparinization, the subclavian artery was cannulated with a catheter for monitoring of coronary perfusion pressure. The venae cavae and brachiocephalic artery were tied, followed by crossclamping of the descending aorta and ligation of the main pulmonary artery. Cardioplegic arrest was achieved by infusion of cold hyperkalemic crystalloid solution $(750 \mathrm{ml}$ of Normosol with $20 \mathrm{mEq}$ potassium chloride, $5^{\circ} \mathrm{C}$, adjusted to $\mathrm{pH} 7.5$ ) into the previously placed subclavian arterial tubing. The heart was then excised and placed in $10^{\circ} \mathrm{C}$ Normosol solution.

During the 90-minute hypothermic arrest period, the heart was prepared for the ex vivo circuit. The brachiocephalic artery was cannulated for retrograde coronary perfusion and the right ventricle for coronary sinus drainage. A plastic $\mathrm{O}$ ring was sutured to the mitral anulus for mounting to the servo pump.

After 90 minutes of hypothermic ischemia, the heart was cleared of air in a basin of warm Normosol solution and reperfusion was begun at $40 \mathrm{~mm} \mathrm{Hg}$ for the initial 10 minutes, then increased to 70 to $80 \mathrm{~mm} \mathrm{Hg}$ for the remainder of the experiment. After being mounted on the servo apparatus, the left ventricular balloon was secured through an apical stab wound. Epicardial pacing wires were placed and pacing was maintained at 150 beats $/ \mathrm{min}$ (Grass Instrument Co., Quincy, Mass.). The temperature of the blood in the circuit was maintained at $37^{\circ} \mathrm{C}$ by a heat exchanger.

Experimental protocol. An outline of the experimental protocol is shown in Fig. 1. The postischemic hearts were reperfused with warm oxygenated blood from the support animal for 30 minutes before baseline data collection was begun. Data collection through a range of diastolic loading conditions was performed in 30-minute intervals. In nine heart preparations, $\mathrm{T}_{3}$ (Triostat, SmithKline Beecham Pharmaceuticals, Philadelphia, Pa.) was given as a $0.2 \mu \mathrm{g} / \mathrm{kg}$ bolus after 1 hour of baseline data collection. A 30-minute equilibration period was then allowed before resuming data collection every 30 minutes for a total period of 90 minutes. A second group of animals $(n=6)$ received reverse $T_{3}$ (rT3, Sigma Chemical Co., St. Louis, 
Mo.) as a $0.2 \mu \mathrm{g} / \mathrm{kg}$ bolus dose and similar measurements were taken.

The isolated heart preparation, a modification of the method of Sagawa and coworkers, ${ }^{17}$ uses a computerized servo pump equipped with a mock circulatory system to collect a set of pressure-volume loops under a constant afterload and a range of increasing diastolic filling pressures set by the investigator. The left ventricular pressure, left ventricular volume, coronary perfusion pressure, and coronary sinus outflow were measured simultaneously and collected at $250 \mathrm{~Hz}$ by custom data software. Blood samples were collected at the same time for determination of the $\mathrm{MVO}_{2}$. The heart was allowed to equilibrate for 3 to 5 minutes at each preload setting before data collection. A minimum of four loading conditions was measured for each data set.

Blood was taken for measurement of serum $T_{3}$ levels during placement of intravenous lines (baseline) from both support and donor animals. Support animals had subsequent blood withdrawal via the circuit at the end of baseline data collection and then 1 hour after drug administration. Whole blood was centrifuged and the serum was stored at $-5^{\circ} \mathrm{C}$. Hormone levels were determined by radioimmunoassay at a commercial animal laboratory (Animal Medical Center, New York, N.Y.).

Measurement of parameters

Analysis of left ventricular function and PVA. The left ventricular performance was derived from analysis of the stroke work/end-diastolic volume relationship, which yielded an $\mathrm{x}$ intercept, slope, and the preload recruitable stroke work area (PRSWA) extrapolated to an enddiastolic volume of $100 \mathrm{ml}^{18}$ at each data interval.

Total mechanical energy production was measured as the PVA for each preloading condition with the use of custom software modeled after the method of Sagawa and colleagues. ${ }^{19}$ These PVAs are plotted against the corresponding $\mathrm{MVO}_{2}$ values to generate the PVA- $\mathrm{MVO}_{2}$ relationship.

$\mathrm{MVO}_{2}$. Aortic and coronary sinus oxygen tension $\left(\mathrm{PO}_{2}\right)$, oxygen saturation, and hemoglobin $(\mathrm{HgB})$ were measured by a blood gas $/ \mathrm{pH}$ analyzer and a Co-Oximeter device (Instrumentation Laboratory Inc., Lexington, Mass.). $\mathrm{MVO}_{2}$ per cardiac cycle was calculated as $\left(\left[\mathrm{CaO}_{2}-\mathrm{Cvo}_{2}\right]\right.$ $\times$ coronary flow)/wet left ventricular weight $\times$ heart rate. $\mathrm{CaO}_{2}$ and $\mathrm{Cvo}_{2}$ denote arterial and venous oxygen content, respectively. Oxygen content was calculated as $(1.38 \times$ $\mathrm{Hgb} \times$ percent saturation of $\mathrm{Hgb})+\left(0.003 \times \mathrm{PO}_{2}\right)$. $\mathrm{MVO}_{2}$ in milliliters of oxygen per $100 \mathrm{gm} \cdot$ beat was converted into $\mathrm{mm} \mathrm{Hg} \cdot \mathrm{ml} / 100 \mathrm{gm} \cdot$ beat by multiplying 20 joules $/ \mathrm{ml}$ of oxygen and $7502 \mathrm{~mm} \mathrm{Hg} \cdot \mathrm{ml} /$ joule.

Coronary resistance. The resistive component $(\mathrm{mm}$ $\mathrm{Hg} \cdot \mathrm{min} / \mathrm{ml}$ ) of the coronary vascular impedance was calculated as the mean coronary perfusion pressure divided by the mean coronary flow after 3 to 5 minutes of equilibration at each diastolic loading condition.

Diastolic constant. Diastolic function is expressed in terms of the diastolic stiffness constant $\left(\mathrm{k}_{\mathrm{D}}\right)$ of the exponential equation describing the end-diastolic pressurevolume relationship $\mathrm{P}=\mathrm{be}^{\mathrm{kv}}$, where $\mathrm{P}$ and $\mathrm{V}$ represent end-diastolic pressure and volume, respectively, and $\mathrm{b}$ is the left ventricular pressure extrapolated to zero volume. $^{20}$
Statistical methods. All values are expressed as the mean plus and minus the standard error. For each individual experiment, the two baseline data sets were averaged as were the three posttreatment data sets. Baseline data were then pooled for statistical comparison to pooled posttreatment data. Comparisons within and between experimental groups were performed with paired and two-sample $t$ tests, respectively. Coronary resistance and flow data were analyzed by analysis of variance with repeated measures. A $p$ value of less than 0.05 was considered statistically significant.

\section{Results}

$\mathbf{T}_{\mathbf{3}}$ levels. Total serum $\mathrm{T}_{3}$ levels were normal in both donor and support animals at the onset of the experiment. After the initiation of cross-perfusion, mean serum $\mathrm{T}_{3}$ levels in the support animals decreased from $0.55 \pm 0.07$ to $0.13 \pm 0.01 \mu \mathrm{g} / \mathrm{dl}(p<$ 0.01 ). This decrease was associated with an average drop in hemoglobin value from 13 to $9.8 \mathrm{gm} / \mathrm{dl}$. Mean $\mathrm{T}_{3}$ levels subsequently rose to $0.58 \pm 0.05$ $\mu \mathrm{g} / \mathrm{dl}(p<0.01) 60$ minutes after the $\mathrm{T}_{3}$ bolus. In the experiments in which $\mathrm{rT}_{3}$ was used, serum $\mathrm{T}_{3}$ levels dropped to a mean value of $0.10 \pm 0.01 \mu \mathrm{g} / \mathrm{dl}(p<$ 0.01 ) and did not rise after the $\mathrm{rT}_{3}$ bolus.

Contractility. The changes in intrinsic myocardial contractility were evaluated by analysis of the PRSWA before and after $T_{3}$ or $\mathrm{rT}_{3}$ administration. Data collected during the pre- $\mathrm{T}_{3}$ period (baseline) were pooled, as were the post- $\mathrm{T}_{3}$ data (Fig. 2). Administration of $T_{3}$ to postischemic hearts improved the PRSWA from $9.5 \pm 1.42$ to $14.9 \pm 2.03$ $\times 10^{7} \mathrm{erg} / \mathrm{ml}$, a $56 \%$ increase over baseline that was highly significant $(p<0.001)$. Administration of the biologically inactive metabolite $\mathrm{rT}_{3}$ did not change contractility compared with baseline $(8.82 \pm 1.40$ to $\left.8.16 \pm 1.31 \times 10^{7} \mathrm{erg} / \mathrm{ml}\right)$. The hearts treated with $\mathrm{T}_{3}$ and $\mathrm{rT}_{3}$ in this set of experiments did not differ significantly at baseline with respect to PRSWA. Prior analysis of a group of untreated postischemic as well as continuously perfused, nonischemic hearts revealed no significant change in PRSWA over a 3-hour time period (manuscript in preparation). Administration of $T_{3}$ to the nonischemic, normal hearts was without significant effect on contractility $\left(9.79 \pm 1.15\right.$ to $\left.8.42 \pm 0.97 \times 10^{7} \mathrm{erg} / \mathrm{ml}\right)$.

PVA-MVO ${ }_{2}$. Data from each experiment were analyzed individually and then pooled for statistical

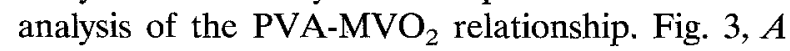
and $B$ shows the linear regressions for each experimental group as labeled. The two groups did not differ significantly from each other at baseline. Although $\mathrm{T}_{3}$ treatment was associated with a pro- 


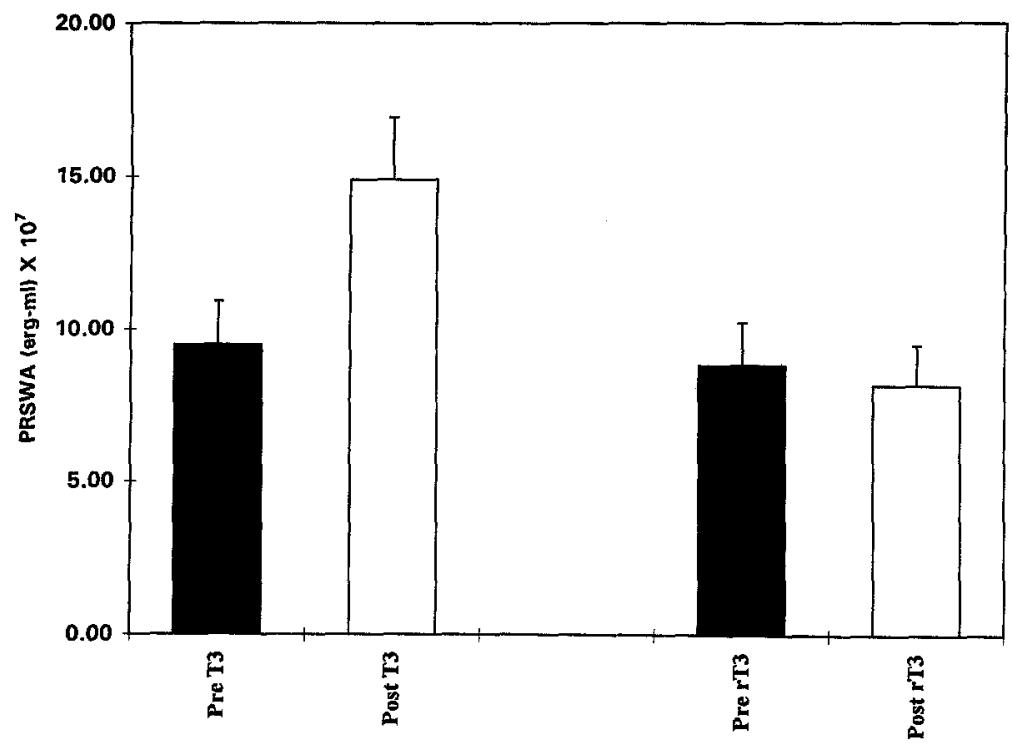

Fig. 2. Effect of $T_{3}$ and $r T_{3}$ on intrinsic myocardial contractility. All values are expressed as the mean \pm the standard error of the mean. ${ }^{*} p<0.001$ versus pre $\mathrm{T}_{3}$ by paired $t$ test and versus pre and post rT3 by two-sample $t$ test.

nounced inotropic effect, the PVA- $\mathrm{MVO}_{2}$ relationship was not significantly altered. The y intercepts were 4414 and $4411 \mathrm{~mm} \mathrm{Hg} \cdot \mathrm{ml} / 100 \mathrm{gm} \cdot$ beat and the slopes 2.45 and 2.58 before and after $\mathrm{T}_{3}$ treatment. No significant changes in the y intercept or slope occurred after $\mathrm{rT}_{3}$ bolus.

Diastolic function. Left ventricular diastolic function was expressed as the diastolic stiffness constant $\left(\mathrm{k}_{\mathrm{D}}\right)$, as derived from the exponential equation $\mathrm{P}=$ $\mathrm{be}^{\mathrm{kv}}$ describing the left ventricular end-diastolic pressure-volume relationship (Table I). Although compliance decreased in both groups, neither change was statistically significant.

Coronary vascular responses. The coronary vascular resistance was calculated from the aortic root or coronary perfusion pressure divided by the coronary flow measured after 3 to 5 minutes of equilibration through a range of diastolic loading conditions (Table II). These were arbitrary settings corresponding to end-diastolic ventricular pressures in the range of 4 to $20 \mathrm{~mm} \mathrm{Hg}$. $\mathrm{T}_{3}$ significantly reduced coronary resistance throughout the range of loading conditions in the ischemic reperfused hearts. This reduction in coronary vascular resistance in the $T_{3}$-treated hearts resulted in a significant increase in blood flow at each diastolic pressure setting, as shown in Table III. $\mathrm{rT}_{3}$ did not alter coronary vascular resistance or flow rate.

\section{Discussion}

Recently, interest has focused on the effects of an acute deficiency of circulating total and free $T_{3}$ arising as a consequence of $\mathrm{CPB}^{5,6,21}$ on postoperative cardiac performance. Several studies have suggested that $T_{3}$ repletion in this setting has hemodynamic benefits. Novitzky and colleagues reported an improvement in postischemic left ventricular function after experimental CPB and cardioplegic arrest in pigs ${ }^{7}$ and $\operatorname{dogs}^{8}$ that had received $\mathrm{T}_{3}$ after removal of the aortic crossclamp. These studies, however, used load-dependent parameters of ventricular function that do not accurately reflect primary cardiac effects. Dyke and associates ${ }^{11}$ using an isolated rabbit heart model, found that $T_{3}$ treatment administered immediately at the time of reperfusion restored peak developed pressure after ischemia. A more recent report from this group describes improved load-independent ventricular function (using the stroke work-end-diastolic volume relationship) in response to $T_{3}$ treatment in an experimental model of CPB. ${ }^{9}$ Both studies, however, involved severe warm ischemic injury and did not investigate the relationship between cardiac work and $\mathrm{MVO}_{2}$.

The goal of this study was to characterize the effects of $T_{3}$ administered immediately on loadindependent parameters of left ventricular function and on myocardial energetics in a model of hypo- 

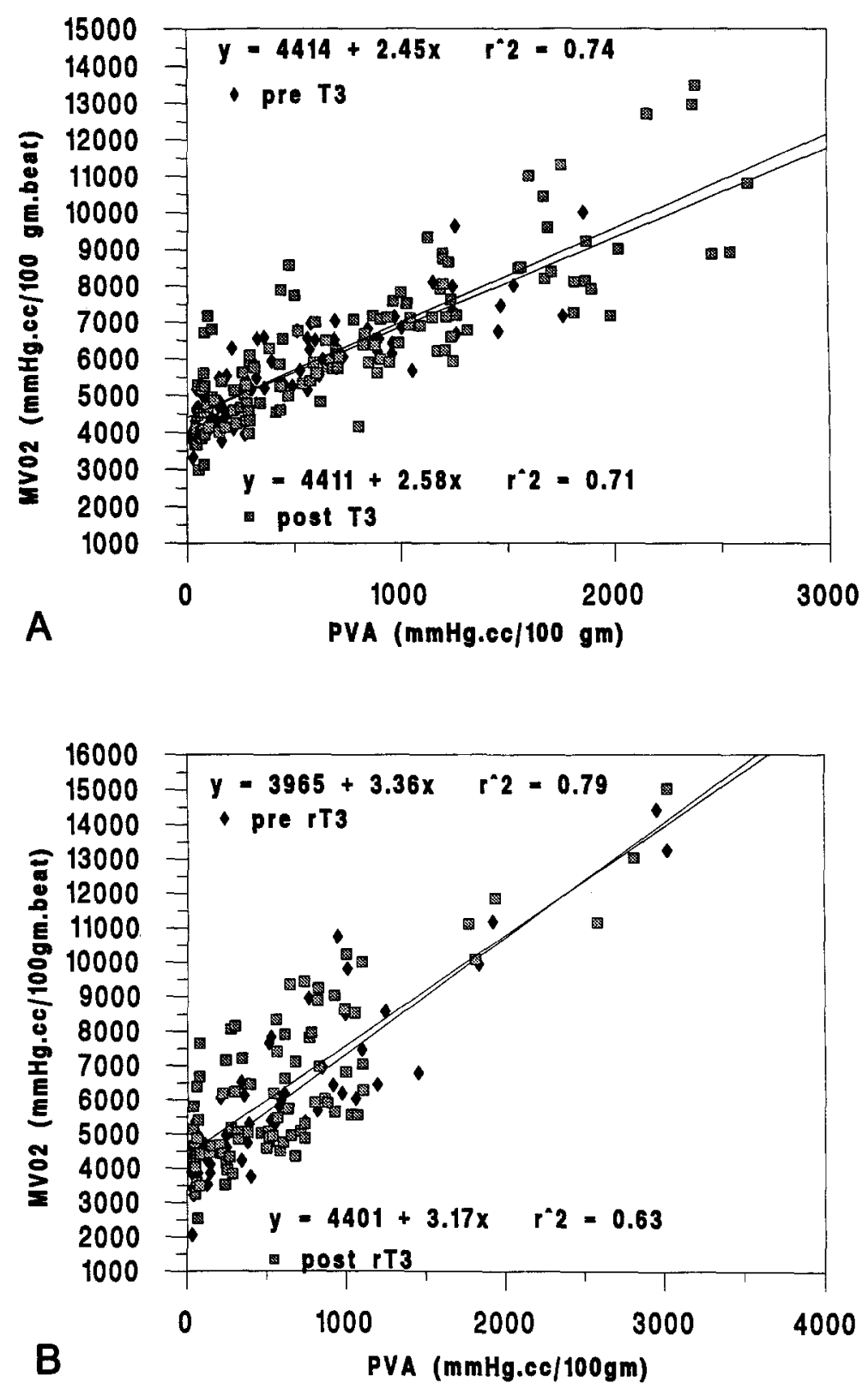

Fig. 3. Effect of $\mathrm{T}_{3}(\mathrm{~A})$ and $\mathrm{rT}_{3}(\mathbf{B})$ on the PVA-MVO $\mathrm{M}_{2}$ relationship in postischemic hearts. Straight lines represent the linear regressions of the data sets as labeled.

thermic global ischemia designed to mimic the clinical situation encountered in the peri-CPB or transplantation period. The ex vivo isolated heart preparation eliminates variability in left ventricular loading conditions and establishes a hormonal environment that approximates clinical CPB.

The observed $65 \%$ to $75 \%$ drop in the total serum $\mathrm{T}_{3}$ levels of the support animals correlates with clinical experience. ${ }^{5,6}$ Although the mechanism un-
Table I. Left ventricular function: diastolic stiffness constant $(k) *$

\begin{tabular}{lcc}
\hline & Baseline & $\begin{array}{c}\text { After } \\
\text { treatment }\end{array}$ \\
\hline Postischemic + T3 & $0.068 \pm 0.009$ & $0.090 \pm 0.021$ \\
Postischemic + rT3 & $0.058 \pm 0.007$ & $0.097 \pm 0.023$ \\
\hline
\end{tabular}

All values are mean \pm standard error of the mean.

*Derived from the equation $\mathbf{P}=\mathrm{be}^{\mathrm{kv}}$ describing the end-diastolic pressure-volume relationship. 
Table II. Coronary vascular resistance

\begin{tabular}{|c|c|c|c|c|}
\hline & \multicolumn{4}{|c|}{ Diastolic loading conditions* } \\
\hline & 5 & 15 & 25 & 35 \\
\hline \multicolumn{5}{|l|}{ Postischemic } \\
\hline Baseline & $0.733 \pm 0.067$ & $0.681 \pm 0.06$ & $0.575 \pm 0.05$ & $0.538 \pm 0.04$ \\
\hline Post $\mathbf{T}_{3}$ & $0.581 \pm 0.035 \dagger$ & $0.507 \pm 0.035 \dagger$ & $0.464 \pm 0.030 \ddagger$ & $0.421 \pm 0.027 \uparrow$ \\
\hline \multicolumn{5}{|c|}{ Postischemic } \\
\hline Baseline & $0.703 \pm 0.152$ & $0.614 \pm 0.04$ & $0.563 \pm 0.065$ & $0.509 \pm 0.058$ \\
\hline Post $\mathrm{rT}_{3}$ & $0.674 \pm 0.115$ & $0.601 \pm 0.096$ & $0.553 \pm 0.073$ & $0.491 \pm 0.064$ \\
\hline
\end{tabular}

Coronary resistance expressed in means \pm standard error of the mean $(\mathrm{mm} \mathrm{Hg} \cdot \mathrm{min} / \mathrm{ml})$ for four diastolic loading conditions.

*Arbitrary loading conditions corresponding to end-diastolic pressures ranging from 4 to $20 \mathrm{~mm} \mathrm{Hg}$.

$t p<0.05$ versus corresponding baseline values by analysis of variance.

$\ddagger p=0.06$ versus corresponding baseline values by analysis of variance.

derlying this decrease was not addressed, it could not be completely attributed to the hemodilution related to the preparation. An acute stress response resulting from the inherent trauma of extracorporeal circulation and the added work imposed by the ex vivo heart on the support dog may have contributed to the low $\mathrm{T}_{3}$ state in this model as a result of decreased peripheral conversion of thyroxine $\left(\mathrm{T}_{4}\right)$ to $\mathrm{T}_{3}$, shortened half-life of $\mathrm{T}_{3}$, and/or altered volume of distribution for the hormone.

Our isolated heart preparation is similar to previously described animal models of hyperkalemic cardioplegic arrest followed by a period of global, hypothermic ischemia in which systolic function is preserved. ${ }^{22-24}$ However, whether $T_{3}$ could affect the performance of hearts subjected to a period of protected hypothermic ischemia followed by reperfusion has not been tested in a setting where loading conditions are carefully controlled.

In the present study, $T_{3}$ treatment resulted in a $56 \%$ increase in PRSWA in the postischemic hearts. In agreement with an earlier report, ${ }^{11}$ no inotropic response to $T_{3}$ was observed in the nonischemic, continuously perfused hearts. Similar to the myocardium injured by normothermic ischemia, ${ }^{9-11} \mathrm{~T}_{3}$ augmented ventricular performance in the hypothermic arrested myocardium. This is consistent with data reported by Novitzky and associates, ${ }^{7}$ in which $T_{3}$ treatment in a porcine model of $\mathrm{CPB}$, with protected cardioplegic arrest, resulted in a peak developed pressure greater than baseline. The PRSWA is an index of intrinsic myocardial contractility independent of loading conditions and is recognized as a more sensitive measure of ventricular performance. $^{25,26}$

One emphasis of this study was to characterize the effects of $T_{3}$ on myocardial energetics in terms of efficiency, namely, the ratio of total mechanical energy production to total myocardial energy consumption. The linearity of the $\mathrm{PVA}-\mathrm{MVO}_{2}$ relationship has been well described. ${ }^{27}$ The slope of this regression is inversely proportional to the efficiency of energy use, and the extrapolated $y$ intercept represents the energy requirement of the unloaded contracting ventricle. Traditional $\beta$-agonist inotropic agents such as dobutamine ${ }^{16,21}$ and epinephrine $^{28}$ shift the $P V A-\mathrm{MVO}_{2}$ regression line upward. This elevation of the $y$ intercept represents an "oxygen wasting effect" in which an increased amount of energy is required in the enhanced state compared with the normal state for the same level of total work. $\mathrm{T}_{3}$, in the dose of $0.2 \mu \mathrm{g} / \mathrm{kg}$, restored serum $\mathrm{T}_{3}$ to physiologic levels and produced a significant inotropic effect without incurring additional oxygen debt. The PVA- $\mathrm{MVO}_{2}$ relationship was similar before and after $\mathrm{T}_{3}$ administration. The PVA-MVO $\mathrm{MV}_{2}$ relationship was unaffected by $\mathrm{rT}_{3}$ treatment, which showed no inotropic effect. Conflicting, though perhaps species-dependent, descriptions of the PVA- $\mathrm{MVO}_{2}$ relationship in the chronically hyperthyroid left ventricle have been reported. $^{29,30}$ The acute effects of $T_{3}$ treatment in a hormonally depleted environment represent a fundamentally different situation, and this report is the first to directly characterize myocardial energetics in this setting.

One effect of thyroid hormones is a decrease in peripheral vascular resistance. ${ }^{14,15}$ Recent studies suggest that $T_{3}$ may act as a direct vasodilator on arterial smooth muscle cells, ${ }^{15,}{ }^{31}$ yet its influence on coronary arterial tone has not been established. Our data suggest that $T_{3}$ may substantially increase blood flow to the coronary bed. Coronary resistance is determined by perfusion pressure and flow. Flow is most dependent on the demand of the myocardium, which is strongly influenced by the loading 


\begin{tabular}{ccccc}
\hline & \multicolumn{4}{c}{ Diastolic loading conditions* } \\
\cline { 2 - 5 } & 5 & 15 & 25 & 35 \\
\hline Postischemic & $109 \pm 9.6$ & $115.6 \pm 8.9$ & $136.9 \pm 11.1$ & $150.2 \pm 11.3$ \\
Baseline & $140.7 \pm 14.5 \dagger$ & $167.3 \pm 17 \dagger$ & $181.4 \pm 17.3 \dagger$ & $198.4 \pm 14.2 \dagger$ \\
$\quad \begin{array}{c}\text { Post } \mathrm{T}_{3} \\
\text { Postischemic }\end{array}$ & $120 \pm 17.2$ & $131.4 \pm 17.6$ & $141.7 \pm 15.7$ & $157.4 \pm 15.6$ \\
Baseline & $126 \pm 17.3$ & $135.6 \pm 18$ & $147.4 \pm 18.2$ & $163.5 \pm 21.4$ \\
Post $\mathrm{rT}_{3}$ & & & \\
\hline
\end{tabular}

Coronary flow expressed in means \pm standard error of the mean $(\mathrm{ml} / \mathrm{min})$ for four diastolic loading conditions.

*Arbitrary loading conditions corresponding to end-diastolic pressures ranging from 4 to $20 \mathrm{~mm} \mathrm{Hg}$.

$\dagger p<0.05$ versus corresponding baseline values by analysis of variance.

conditions and contractile activity of the heart. The isolated heart model, in which coronary perfusion pressure and afterload can be kept constant, is well suited for examining changes in vascular tone. Although it is difficult to distinguish a primary vasodilatory effect from a response to the enhanced contractile state, the finding that the augmentation of contractility occurred without additional oxygen requirement supports such an effect. Kadletz and coworkers $^{32}$ have recently reported that $\mathrm{T}_{3}$ did not increase coronary flow in a rat heart Langendorff preparation involving warm ischemia. Several differences in method may account for the discrepancy. The two models differ in type of injury, perfusate, and sampling time relative to reperfusion. We have noted that during the initial period of reperfusion, the postischemic hearts are markedly hyperemic. If data collection is obtained before a sufficient interval of stabilization after reperfusion is completed, it is possible that an already dilated coronary vasculature may not be additionally influenced by $\mathrm{T}_{3}$ administration.

Although the present model does not provide a molecular basis for the effects of $T_{3}$ on left ventricular function, the rapidity of onset of the effect suggests an extranuclear mechanism. Despite intensive investigation into the interaction with several cell membrane and enzyme systems, ${ }^{33}$ the mechanism(s) responsible for the acute action of $T_{3}$ are not well defined. The inotropic action of $T_{3}$ on the postischemic myocardium may relate to alterations in intracellular and transcellular calcium handling after injury. Ischemia-reperfusion may result in profound disturbances in intracellular calcium ${ }^{34}$ and sodium $^{35}$ balance, along with depression of key enzyme systems such as calcium adenosinetriphosphatase in the sarcoplasmic reticulum. ${ }^{36,37}$ The known effects of $T_{3}$ on myocardial calcium han- dling $^{38-40}$ and sodium channel activity ${ }^{41}$ suggest potential routes through which the postischemic myocardium may be acutely responsive to $T_{3}$ treatment. Although $T_{3}$ is known to affect left ventricular diastolic function, ${ }^{2,42}$ we did not observe significant change after $T_{3}$ administration. This analysis, however, did not measure the rate of diastolic relaxation.

Some interesting comparisons between $\mathrm{T}_{3}$ and bipyridine phosphodiesterase inhibitors can be made. At a biochemical level, $\mathrm{T}_{3}$ and milrinone were reported to display structural and functional homologies. ${ }^{43}$ In addition, the relationship between inotropic effect and oxygen utilization efficiency observed with $T_{3}$ is similar to that reported for amrinone. ${ }^{16}$ Finally, Caldarone and associates ${ }^{44}$ have described an inotropic specificity of milrinone for the postischemic reperfused heart with no effect on normal hearts.

In summary, the ex vivo isolated heart preparation cross-circulated by a support dog was found to be a useful model for evaluating the effects of acute $\mathrm{T}_{3}$ administration in a hormonal environment that mimics the clinical condition of CPB. Specificity for the postischemic myocardium has been suggested by earlier experimental literature, and, despite preservation of left ventricular contractility in our model, the ischemic interval followed by reperfusion allowed an inotropic effect of $\mathbf{T}_{3}$ to be manifest. This report is the first to characterize the acute effects of $\mathrm{T}_{3}$ on the postischemic heart with respect to the PVA- $\mathrm{MVO}_{2}$ relationship and clearly shows that $\mathrm{T}_{3}$ augmentation of postischemic left ventricular function occurs without oxygen wasting effects. In addition, $T_{3}$ appears to have a vasodilatory effect on the coronary vasculature. Together, these findings lend additional support for repleting $\mathrm{T}_{3}$ levels in the setting of myocardial ischemia-reperfusion. 
We thank Howard Thaler, PhD for statistical consultation. We also thank SmithKline Beecham Pharmaceuticals, Philadelphia, for the generous supply of triiodothyronine (Triostat).

\section{REFERENCES}

1. Klein I. Thyroid hormone and the cardiovascular system. Am J Med 1990;88:631-7.

2. Mintz G, Pizzarello R, Klein I. Enhanced left ventricular diastolic function in hyperthyroidism: noninvasive assessment and response to treatment. J Clin Endocrinol Metab 1991;73:146-50.

3. Dillmann W. Biochemical basis of thyroid hormone action in the heart. Am J Med 1990;88:626-30.

4. Polikar R, Burger AG, Scherrer U, Nicod P. The thyroid and the heart. Circulation 1993;87:1435-41.

5. Holland FW, Brown PS, Weintraub BD, Clark RE. Cardiopulmonary bypass and thyroid function: a "euthyroid sick syndrome." Ann Thorac Surg 1991;52:4650 .

6. Robuschi G, Medici D, Fesani F, et al. Cardiopulmonary bypass: 'a low T4 and T3 syndrome' with blunted thyrotropin (TSH) response to thyrotropic-releasing hormone (TRH). Horm Res 1986;23:151-8.

7. Novitzky D, Human PA, Cooper DKC, et al. Inotropic effect of triiodothyronine following myocardial ischemia and cardiopulmonary bypass: an experimental study in pigs. Ann Thorac Surg 1988;45:50-5.

8. Novitzky D, Matthews N, Shawley D, et al. Triiodothyronine in the recovery of the stunned myocardium in dogs. Ann Thorac Surg 1991;51:10-7.

9. Dyke CM, Ding M, Abd-Elfattah AS, et al. Effects of triiodothyronine supplementation after myocardial ischemia. Ann Thorac Surg 1993;56:215-22.

10. Holland FW, Brown PS, Clark RE. Acute severe postischemic myocardial depression reversed by triiodothyronine. Ann Thorac Surg 1992;54:301-5.

11. Dyke CM, Yeh T, Lehman JD, et al. Triiodothyronine-enhanced left ventricular function after ischemic injury. Ann Thorac Surg 1991;52:14-9.

12. Novitzky D, Cooper DKC, Barton CI, et al. Triiodothyronine as an inotropic agent after open heart surgery. J THORAC CARDIOVASC SURG 1989;98:972-8.

13. Novitzky D, Cooper DKC, Swanepoel A. Inotropic effect of triiodothyronine $\left(\mathrm{T}_{3}\right)$ in low cardiac output following cardioplegic arrest and cardiopulmonary bypass: initial experience in patients undergoing open heart surgery. Eur J Cardiothorac Surg 1989;3:140-5.

14. Graettinger JS, Muenster JJ, Selverstone LA, Campbell JA. A correlation of clinical and hemodynamic studies in patients with hyperthyroidism and without congestive heart failure. J Clin Invest 1959;38:131627.

15. Ojamaa K, Balkman C, Klein I. Acute effects of triiodothyronine on arterial smooth muscle cells. Ann Thorac Surg 1993;56:S61-7.

16. Ko W, Zelano JA, Fahey L, et al. The effects of amrinone versus dobutamine on myocardial mechanics and energetics after hypothermic global ischemia. J Thorac Cardiovasc SuRg 1993;105:1015-24.

17. Sagawa K, Maughan L, Suga H, Sunagawa K. Methods for studying the pressure-volume relationship. In: Sagawa K, Maughan L, Suga H, Sunagawa K, eds. Cardiac contraction and the pressure-volume relationship. New York: Oxford University Press, 1988: 370-474.

18. Glower DD, Spratt JA, Snow ND, et al. Linearity of the Frank-Starling relationship in the intact heart: the concept of preload recruitable stroke work. Circulation 1985;17:994-1009.

19. Sagawa K, Maughan L, Suga H, Sunagawa K. Energetics of the heart. In: Sagawa K, Maughan L, Suga H, Sunagawa $\mathrm{K}$, eds. Cardiac contraction and the pressure-volume relationship. New York: Oxford University Press, 1988:171-231.

20. Gaasch WH, Apstein CS, Levine HJ. Diastolic properties of the left ventricle. In: Levine HJ, Gaasch WH, eds. The ventricle: basic and clinical aspects. Boston: Martinus Niijhoff Publishing, 1985:143-70.

21. Clark R. Cardiopulmonary bypass and thyroid hormone metabolism. Ann Thorac Surg 1993;56:S35-42.

22. Swanson DK, Dufek JH, Kahn DR. Left ventricular function after preserving the heart for 2 hours at $15^{\circ}$ C. J Thorac Cardiovasc Surg 1980;79:755-60.

23. Krukenkamp IB, Silverman NA, Sorlie D, et al. Characterization of postischemic myocardial oxygen utilization. Circulation 1986;74(Suppl):III125-9.

24. Ko W, Zelano J, Lazzaro R, et al. Optimal. storage period for extended heart preservation with the University of Wisconsin solution: a study of the left ventricular pressure-volume relationship. J Cardiovasc Surg 1992;33:204-10.

25. Glower DD, Spratt JA, Kabas S, Davis JW, Rankin JS. Quantification of regional myocardial dysfunction after acute ischemic injury. Am J Physiol 1988;255: H85-93.

26. Matsuwaka R, Matsuda H, Shirakura R, et al. Changes in left ventricular performance after global ischemia: assessing LV pressure-volume relationship. Ann Thorac Surg 1994;57:151-6.

27. Nozawa T, Yasumura Y, Futaki S, Tanaka M, Suga H. Relation between oxygen consumption and pressurevolume area of in situ dog heart. Am J Physiol 1987:253:H31-40.

28. Suga H, Hisano R, Goto Y, Yamada O, Igarashi Y. Effect of positive inotropic agents on the relation between oxygen consumption and systolic pressurevolume area in canine left ventricle. Circ Res 1983; 53:306-18.

29. Suga H, Tanaka N, Ohgoshi Y, et al. Hyperthyroid dog left ventricle has the same oxygen consumption versus pressure-volume area (PVA) relation as euthyroid dog. Heart Vessels 1991;6:71-83. 
30. Goto Y, Slinker BK, LeWinter MM. Decreased contractile efficiency and increased non-mechanical energy cost in hyperthyroid rabbit heart: relation between $\mathrm{O}_{2}$ consumption and systolic pressure-volume area or force-time integral. Circ Res 1990;66:9991011.

31. Ishikawa $T$, Chijiwa $T$, Hagiwara $M$, Mamiya $S$, Hiroyoshi $\mathrm{H}$. Thyroid hormones directly interact with vascular smooth muscle strips. Mol Pharmacol 1985; 35:760-5.

32. Kadletz M, Mullen PG, Ding M, Wolfe LG, Wechsler AS. Effect of triiodothyronine on postischemic myocardial function in the isolated heart. Ann Thorac Surg 1994;57:657-63.

33. Davis PJ, Davis FB. Acute cellular actions of thyroid hormone and myocardial function. Ann Thorac Surg 1993;56:S16-23.

34. Marban E, Koretsune Y, Corretti M, Chacko VP, Kusuoka $H$. Calcium and its role in myocardial cell injury during ischemia and reperfusion. Circulation 1989;80(Suppl):IV17.

35. Nayler WG, Perry SE, Elz JS, Daly MJ. Calcium, sodium, and the calcium paradox. Circ Res 1984;55: 227-37.

36. Krause SM, Jacobus WE, Becker LC. Alterations in cardiac sarcoplasmic reticulum calcium transport in the postischemic "stunned" myocardium. Circ Res 1989;65:526-30.

37. Rapundalo ST, Briggs FN, Feher JJ. Effects of ischemia on the isolation and function of canine cardiac sarcoplasmic reticulum. J Moll Cell Cardiol 1986;18: 837-51.

38. Rudinger A, Mylotte KM, Davis PJ, Davis FB, Blas SD. Rabbit myocardial membrane $\mathrm{Ca}^{2+}$ activity: stimulation in vitro by thyroid hormone. Arch Biochem Biophys 1984;229:379-85.

39. Kim D, Smith TW. Effects of thyroid hormone on calcium handling in cultured chick ventricular cells. J Physiol (Lond) 1985;364:131-49.

40. Suko J. Alterations of $\mathrm{Ca}^{2+}$ uptake and $\mathrm{Ca}^{2+}$-activated ATPase of cardiac sarcoplasmic reticulum in hyper and hypothyroidism. Biochem Biophys Acta 1971;252:324-7.

41. Harris DR, Green WL, Craelius W. Acute thyroid hormone promotes slow inactivation of sodium current in neonatal cardiac myocytes. Biochim Biophys Acta 1991;1045:175-81.

42. Vora J, O'Malley BP, Petersen S, McCullough A, Rosenthal FD, Barnett DB. Reversible abnormalities of myocardial relaxation in hypothyroidism. J Clin Endocrinol Metab 1985;61:269-72.

43. Mylotte KM, Cody V, Davis PJ, Davis FB, Blas SD. Milrinone and thyroid hormone stimulate myocardial membrane $\mathrm{Ca}^{2+}$ activity and share structural homologies. Proc Natl Acad Sci U S A 1985;82:7974-8.

44. Caldarone CA, Krukenkamp IB, Burns PG, Misare BD, Gaudette GR, Levitsky S. Ischemia-dependent efficacy of phosphodiesterase inhibition. Ann Thorac Surg 1994;57:540-6. 